\title{
Ligation-Anopexy versus Pile Suture for Treatment of Advanced Hemorrhoidal Disease: Randomized Controlled Study
}

\author{
Khaled S Abbas, $M D, P h D$; \\ Khaled M. Madbouly, MD., Ph.D., MRCS (Glasg); Ahmed M. Hussein, MCh, Dr. \\ Department of Surgery, University of Alexandria, Egypt.
}

The aim of this study was to compare ligation-anopexy and pile suture for treatment of 3ed and 4th degree hemorrhoidal disease.

Patients and methods: 60 patients (28 females) complaining of symptoms of advanced hemorrhoidal disease were included in the study. Patients were divided into two groups, group I underwent ligation-anopexy and group II underwent pile suture. Operating time, post operative pain, time off work, complications and recurrence of symptoms were analyzed.

Results: Mean age in group I was $42.6 \pm 14.04$ while in group II was $40.8 \pm 11.2$ years. The operative time for group I was $18.3 \pm 4.12$ minutes versus $22.8 \pm 7.1$ minutes in group II. The mean follow up for group I was $13.73 \pm 2.12$ months while for group II it was14.21 \pm 2.26 months. Follow up showed that mean visual analog scale for pain in pile suture group was significantly higher at 1st post-operative day $(2.43 \pm 0.94 \mathrm{vs} 4.97 \pm 1.65)$ and at the end of first week (0.43 \pm 0.63 vs1.07 \pm 1.17$)$. Mean time needed for the patients to return to normal activity was slightly lower in group I (5.3 \pm 1.54 days) than in group II (6.90 2.14 days). Post-operative complications included thrombosis which occurred in four patients in group II, Temporary anal spasm occurred in three patients in group I and two patients in group II. Skin tags were the most common complication in both groups. The recurrence of symptoms was significantly higher after pile suture (16.7\%) than after ligation-anopexy (3.3\%).

Conclusion: Anopexy may improve complications and recurrence rate when added to ligation for treatment of advanced hemorrhoidal disease.

\section{Introduction:}

Advanced hemorrhoidal disease (third and fourth degree) is presented clinically by prolapsed lump which requires manual reduction. Other clinical manifestations include painless bleeding, discomfort, hygiene problems and pruritus. ${ }^{1}$ About one third of patients suffering from hemorrhoidal disease seek medical attention.2,3 About 5-10\% of patients do not respond to conservative treatments, so surgical procedures become the treatment of choice for such cases. ${ }^{4}$

Although some studies reported that rubber band ligation is a safe and effective method compared to open technique in 3rd degree symptomatic hemorrhoidal disease, ${ }^{5}$ it is stated in the revised practice parameters for the management of hemorrhoidal disease that hemorrhoidectomy should be offered to patients with grades III or IV. ${ }^{2}$ Hemorrhoidectomy is the most effective treatment for hemorrhoidal disease with the lowest rate of recurrence compared to other modalities but it is associated with high postoperative pain and the highest complication rate. 6

In attempt to decrease the drawbacks of hemorrhoidectomy, several studies tried many surgical devices including surgical scalpel, scissors, monopolar cauterization, bipolar energy, and ultrasonic devices In general, there appears to be no definitive advantage of one over the others. ${ }^{7-11}$

Aigner et al concluded that there is an association between hypervascularization and the incidence of hemorrhoidal disease 
as they found that the terminal branches of the superior rectal artery in patients with hemorrhoidal disease had a significantly larger diameter, greater blood flow, higher peak velocity and acceleration velocity, compared to those of healthy volunteers. ${ }^{12,13}$

These finding may explain the successes rate which occurs after procedures based on decreasing vascularity by hemorrhoidal artery ligation which can be done with or without Doppler guidance.

Pile suture is a simple method introduced by Farag in 1978 in which three interrupted sutures are used to interrupt the blood flow leading to initial congestion followed by gradual shrinkage of prolapsed hemorrhoids. ${ }^{14,15}$

According to sliding anal canal lining theory hemorrhoid disease develop when the supporting tissues of the anal cushions disintegrate leading to downward displacement of the anal cushions. ${ }^{16}$

Depending on this theory Hussein introduced Ligation-anopexy as a minimally invasive simple method to treat advanced hemorrhoids. This procedure was designed to restore fixation of the hemorrhoids cushions to the underlying internal sphincter, reduce hemorrhoids prolapse, and minimize the hemorrhoids blood flow.

The aim of this study is to compare ligationanopexy and pile suture to explore the role of addition of anopexy to hemorrhoidal ligation to decrease recurrence of symptoms.

\section{Patients and methods:}

This was a prospective randomized trail which included 60 patients with grade III or IV hemorrhoid disease admitted to Unit of Colon and Rectal Surgery, Alexandria Main University Hospital. Study was done between December 2010 and December 2013.

Informed consent was obtained from each patient. The study protocol was approved by the Ethical Committee at Faculty of Medicine, University of Alexandria.

The study compared 30 patients undergoing ligation-anopexy (group I) versus 30 patients undergoing pile suture (group II) for advanced hemorrhoidal disease, in which medical treatment failed. Patients with concomitant ano-rectal disorder were excluded.

Patients of group I underwent ligationanopexy Figures (1-4). ${ }^{15}$ Group II patients underwent pile suture according to Farag's technique ${ }^{15}$ with a suture passed through the mucous membrane at the proximal end of the internal haemorrhoids in order to occlude the superior haemorrhoidal vessels as they enter the internal hemorrhoids, and then a second suture was introduced into the distal end of the internal hemorrhoids above the level of the pectinate line, thus interrupting the connection between the internal and external haemorrhoidal plexuses. A third suture was placed between the previous ones. ${ }^{17}$

Variables noted included operating time, post-operative pain, time off work, complications, and recurrence of symptoms. Pain was assessed with visual analogue scale (VAS). Follow up was made in both groups for one year.

\section{Statistical analysis:}

Statistical analysis was done using Statistical Package for Social Sciences (SPSS/version 21) software. Continuous data were reported as mean and standard deviation, while categorical data were presented as percentages. Categorical parameters were compared using Chi-square test while student t-test was used for parametric data. The level of significant was 0.05 .

\section{Results:}

In the current study, the age ranged between 22 years to 77 years with a mean of $42.6 \pm 14.04$ in group I and $40.8 \pm 11.17$ years in group II. There were 15 women in the ligation-anopexy group and 13 women in the pile suture group.

Data from pre-operative history and examination showed no significant difference between both groups regarding type, duration of complains, grade of haemorroidal disease, and associated co-morbidities Table (1).

The operative time for ligation-anopexy group was insignificantly lower than that for pile suture group with a mean of $18.3 \pm 4.12$ minutes versus $22.83 \pm 7.05$. Mean follow up 


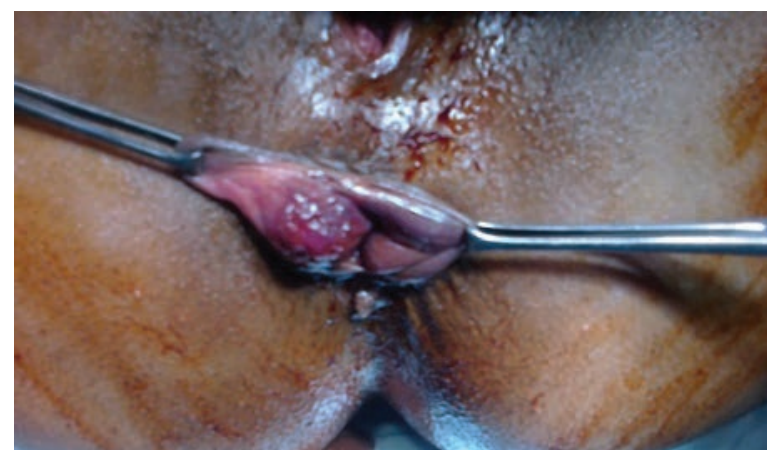

Figure (1): A case of 4th degree hemorrhoidal disease for ligation-anopexy.

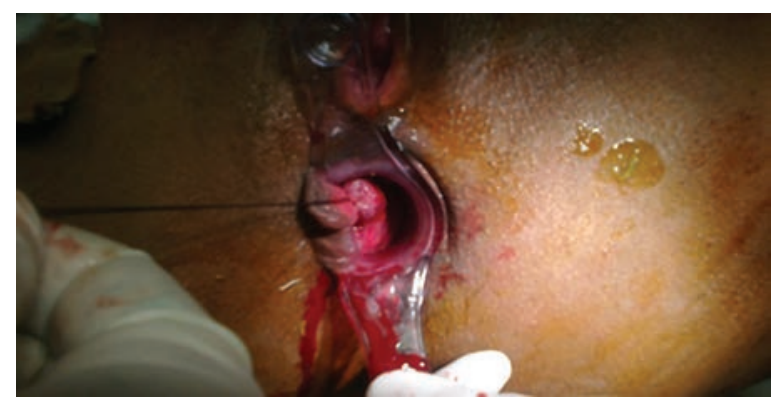

Figure (3): Redundant mucosa is pulled distally to be incorporated in the ligature.

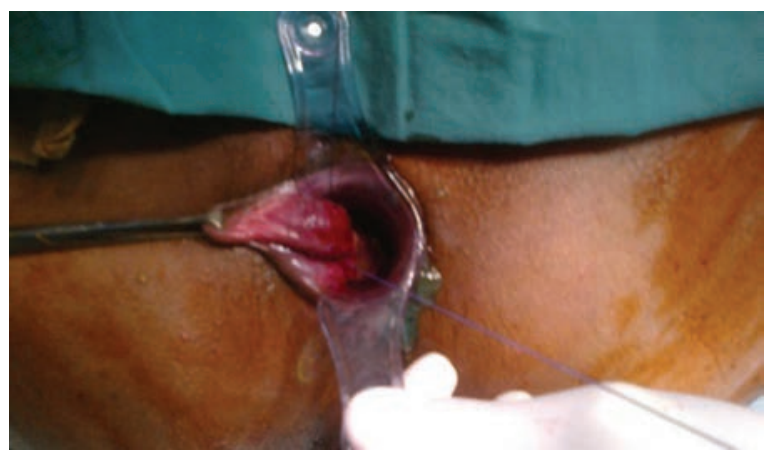

Figure (2): Introduction of the Sims ' speculum and suture to fix the mucosa and the submucosa to the underlying, internal anal sphincter.

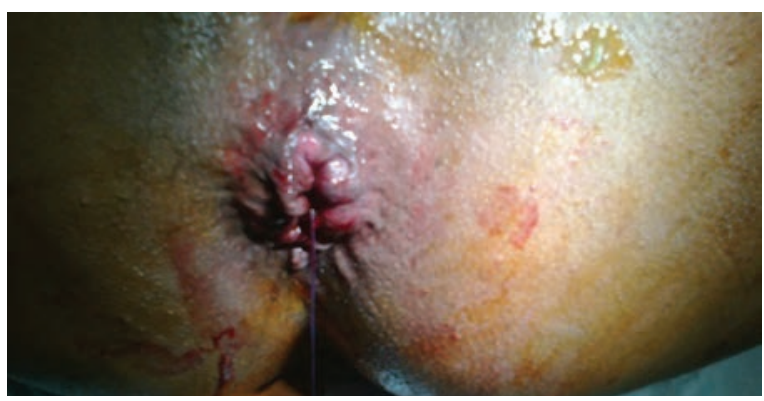

Figure (4): Redundant mucosa is pulled distally to be incorporated in the ligature.

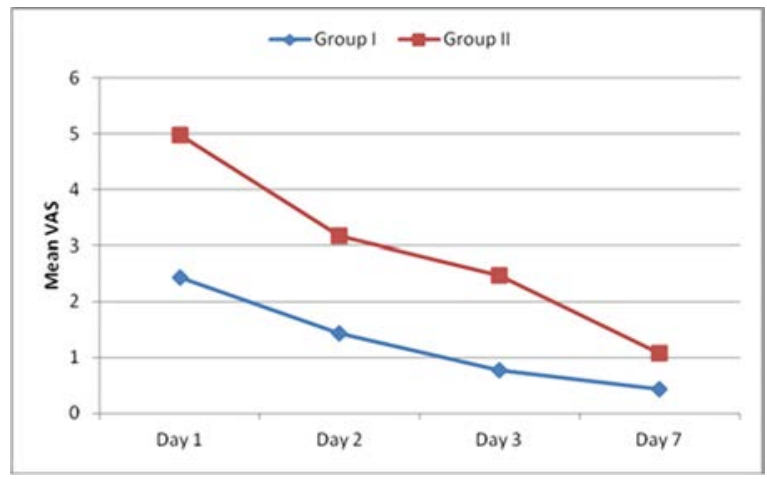

Figure (5): VAS pain score in both groups.

for group I was $13.73 \pm 2.12$ while for group II it was $14.21 \pm 2.26$ months.

Early follow up showed that post-operative pain in pile suture group was significantly higher at 1st post-operative day (2.43 \pm 0.94 vs $4.97 \pm 1.65)$ and remain significantly higher till the end of first week $(0.43 \pm 0.63$ vs. 1.07 $\pm 1.17)$. Figure 5

Mean time needed for the patients to return to normal activity was slightly lower in group I ( $5.3 \pm 1.54$ days) than in group II (6.90 \pm 2.14 days), however this was statistically insignificant.
Post-operative complications included thrombosis which occured in 4 patients of group II and respond to medical treatment. Temporary anal spasm occurs in three patients of group I and two patients of group II. Longer follow up showed that skin tags were the most common complication in both groups as it occurred in $26.7 \%$ and $33.3 \%$ in group I and II respectively. The recurrence of symptoms was significantly higher after pile suture $(16.7 \%)$ than after ligation-anopexy (3.3\%) Table (2). 
Table (1): Clinical data of both groups.

\begin{tabular}{|c|c|c|c|c|c|}
\hline & \multicolumn{2}{|c|}{ Ligation-anopexy $n=30$} & \multicolumn{2}{|c|}{ Pile suture $n=30$} & \multirow[t]{2}{*}{$\mathbf{p}$} \\
\hline & No. & $\%$ & No. & $\%$ & \\
\hline $\begin{array}{l}\text { Duration of } \\
\text { Complain: } \\
\text { Range } \\
\text { Mean } \pm \text { S.D. } \\
\text { Median }\end{array}$ & \multicolumn{2}{|c|}{$\begin{array}{c}4-72 \\
24.8 \pm 17.40 \\
18 \\
\end{array}$} & \multicolumn{2}{|c|}{$\begin{array}{c}5-66 \\
22.70 \pm 18.40 \\
12 \\
\end{array}$} & 0.223 \\
\hline $\begin{array}{l}\text { Complain: } \\
\text { Bleeding } \\
\text { Prolapse } \\
\text { Both } \\
\end{array}$ & $\begin{array}{l}4 \\
7 \\
19 \\
\end{array}$ & $\begin{array}{l}13.3 \\
23.3 \\
63.3 \\
\end{array}$ & $\begin{array}{l}3 \\
7 \\
20\end{array}$ & $\begin{array}{l}10.0 \\
23.3 \\
66.7\end{array}$ & 0.919 \\
\hline $\begin{array}{l}\text { Co-morbidity: } \\
\text { No } \\
\text { BHF } \\
\text { Cardiac disease } \\
\text { Other } \\
\text { co-morbidity }\end{array}$ & $\begin{array}{l}22 \\
3 \\
3 \\
2\end{array}$ & $\begin{array}{l}73.3 \\
10.0 \\
10.0 \\
6.7\end{array}$ & $\begin{array}{l}24 \\
4 \\
1 \\
1\end{array}$ & $\begin{array}{l}80.0 \\
13.3 \\
3.3 \\
3.3\end{array}$ & 0.265 \\
\hline $\begin{array}{l}\text { Haemorrhoid } \\
\text { Grade: } \\
\text { Grade } 3 \\
\text { Grade } 4 \\
\end{array}$ & \begin{tabular}{|l|}
9 \\
21 \\
\end{tabular} & $\begin{array}{l}30.0 \\
70.0 \\
\end{array}$ & $\begin{array}{l}11 \\
19 \\
\end{array}$ & \begin{tabular}{|l|}
36.7 \\
63.3 \\
\end{tabular} & 0.58 \\
\hline $\begin{array}{l}\text { No of columns } \\
1 \\
2 \\
3\end{array}$ & \begin{tabular}{|l}
5 \\
13 \\
12 \\
\end{tabular} & $\begin{array}{l}16.7 \\
43.3 \\
40.0\end{array}$ & $\begin{array}{l}7 \\
10 \\
13\end{array}$ & $\begin{array}{l}23.3 \\
33.3 \\
43.3\end{array}$ & 0.682 \\
\hline
\end{tabular}

Table (2): Complications and recurrence.

\begin{tabular}{|c|c|c|c|c|c|}
\hline & \multicolumn{2}{|c|}{ Group I $n=30$} & \multicolumn{2}{|c|}{ Group II $n=30$} & \multirow{2}{*}{$\mathrm{p}$} \\
\hline & No. & $\%$ & No. & $\%$ & \\
\hline Urine retention & 1 & 3.3 & 0 & 0 & 0.336 \\
\hline Anal spasm & 3 & 10 & 2 & 6.6 & 0.254 \\
\hline Skin tags & 8 & 26.7 & 11 & 33.3 & 0.452 \\
\hline Thrombosis & 0 & 0 & 4 & 13.2 & $0.011 *$ \\
\hline Recurrence & 1 & 3.3 & 5 & 16.7 & $0.048 *$ \\
\hline
\end{tabular}

\section{Discussion:}

In the present study, we compared between two minimally invasive procedures for management of advanced hemorrhoid disease; ligation-anopexy and pile suture. There was no significant difference between both groups regarding demographic data, pre-operative data and operative time.

However the follow up showed that the post-operative pain assessed by VAS was significantly higher after pile suture than after ligation-anopexy along the whole first post-operative week which may be due to the congestion that follow pile suture.

A study on 41 patients treated by hemorrhoidal artery ligation or stapled haemorrhoidopexy reported postoperative pain on a VAS as 1.6 and 3.2 respectively at 7-day follow-up $(\mathrm{p}<0.001)$ and 0.2 and 1.0 respectively at 21 -day follow-up $(p=0.06) .{ }^{18}$

Sung et al reported post-operative pain after Doppler guided HAL comparable with 
that after pile suture in our study at the end of first day and first week. ${ }^{19}$ Dowidar et al reported that post-operative pain assessed by VAS was significantly higher after hemorrhoidectomy when compared with pile suture. ${ }^{17}$

In this study although pain was higher after pile suture, there was no significant difference between the two groups regarding the return to normal activity (5.3 vs. 6.9) days. In a systematic review of 17 studies on hemorrhoidal artery ligation return to normal activity occurred between 2 and 3days after the procedure for most studies. ${ }^{20}$

Early follow up showed that there were no major complications; however thrombosis occurred in $13.2 \%$ of the patient after pile suture which can be explained by stagnation and congestion. Thrombosis was associated by anal spasm in two cases. Anal spasm occurred in three patients after ligationanopexy this may be due to incorporation of internal sphincter in the suture.

Postoperative hemorrhoid thrombosis was reported in 18 (3.6\%) and 3 (3\%) patients in the case series of 507 and 100 patients respectively. In both series HAL was performed without anopexy. ${ }^{21,22}$

In two other case series of 330 and 616 patients in which HAL was performed with anopexy, post-operative thrombosis was reported in $1.6 \%$ and $2.1 \%$ of the patients respectively. So repositioning of the anal cushions by anopexy may decrease congestion that lead to post-operative thrombosis.

Long term follow up showed that incidence of skin tags was $26.7 \%$ after ligation-anopexy and 33.3\% after pile suture. Gupta reported skin tags in only $2.1 \%$ of their cases this may be because most of his cases 616 were grade II and III.

In this study one year follow up showed that recurrence of symptoms was significantly higher after pile suture as recurrence occurred in five patients $(16.7 \%)$, while recurrence occurred in only one patient (3.3\%) after ligation-anopexy. This can be explained by the fact that hemorrhoid disease is not caused by only simple increase of vascularity which is attacked by pile suture but the main pathology is disintegration of supporting tissues of theanal cushions leading to downward displacement of the anal cushions which is corrected by ligation-anopexy.

In a systematic review of 17 studies on hemorrhoidal artery ligation including 1996 patients reported recurrence of bleeding and prolapse in 6\% (40/638) and 8\% (50/638) of patients respectively in 9 studies with followup of less than 1 year; these figures were $10 \%$ (49/507) and 11\% (46/427) respectively in the 6 studies with follow-up of 1 year or more. Out of 17 studies in this systematic review only one study performed anopexy after dearterialisation which may be the cause of this high rate of recurrence. ${ }^{20}$

\section{Conclusion:}

Ligation-anopexy is a simple, safe, effective method for management of advanced hemorrhoidal disease with minimal complications and low recurrence rate. Anopexy may be important to decrease complications and recurrence when added to ligation for treatment of advanced hemorrhoidal disease.

\section{Reference:}

1- DiurniM,DiGiuseppeM:Hemorrhoidectomy in day surgery. Int J Surg 2008; 6 Suppl 1: 53-55.

2- Rivadeneira DE, Steele SR, Ternent C, Chalasani S, Buie WD, Rafferty JL: Practice parameters for the management of hemorrhoids (revised 2010). Dis Colon Rectum 2011; 54: 1059-1064.

3- Madoff RD, Fleshman JW: American Gastroenterological Association technical review on the diagnosis and treatment of hemorrhoids. Gastroenterology 2004; 126 : 1463-1473.

4- Arroyo A, Perez F, Miranda E, Serrano P, Candela F, Lacueva J, Hernandez H, Calpena R: Open versus closed day-case haemorrhoidectomy: is there any difference? Results of a prospective randomised study. Int J Colorectal Dis 2004; 19: 370-373.

5- Khaliq T, Shah SA, Mehboob A: Outcome of rubber band ligation of haemorrhoids using suction ligator. J Ayub Med Coll Abbottabad 2004; 16: 34-37.

6- MacRae HM, McLeod RS: Comparison of hemorrhoidal treatment modalities. A 
meta-analysis. Dis Colon Rectum 1995; 38: 687-694.

7- Khubchandani I: Open vs. closed hemorrhoidectomy. Tech Coloproctol 2005; 9: 256; discussion.

8- Pescatori M: Closed vs. open hemorrhoidectomy: Associated sphincterotomy and postoperative bleeding. Dis Colon Rectum 2000; 43: 1174-1175.

9- You SY, Kim SH, Chung CS, Lee DK: Open vs. closed hemorrhoidectomy. Dis Colon Rectum 2005; 48: 108-113.

10- Chung CC, Cheung HY, Chan ES, Kwok SY, Li MK. Stapled hemorrhoidopexy vs. Harmonic Scalpel hemorrhoidectomy: A randomized trial. Dis Colon Rectum 2005; 48: 1213-1219.

11- Kwok SY, Chung CC, Tsui KK, Li MK: A double-blind, randomized trial comparing Ligasure and Harmonic Scalpel hemorrhoidectomy. Dis Colon Rectum 2005; 48: 344-348.

12- Aigner F, Bodner G, Gruber H, Conrad F, Fritsch H, Margreiter R, Bonatti $\mathrm{H}$ : The vascular nature of hemorrhoids. $J$ Gastrointest Surg 2006; 10: 1044-1050.

13- Aigner F, Gruber H, Conrad F, Eder J, Wedel T, Zelger B, Engelhardt V, Lametschwandtner A, Wienert V, Bohler U, Margreiter R, Fritsch $\mathrm{H}$ : Revised morphology and hemodynamics of the anorectal vascular plexus: Impact on the course of hemorrhoidal disease. Int $J$ Colorectal Dis 2009; 24: 105-113.

14- Awojobi OA: Modified pile suture in the outpatient treatment of hemorrhoids. A preliminary report. Dis Colon Rectum 1983; 26: 95-97.

15- Farag AE. Pile suture: A new technique for the treatment of haemorrhoids. $\mathrm{Br} J$ Surg
1978; 65: 293-295.

16- Dal Monte PP: Doppler-guided hemorrhoidal artery ligation. Tech Coloproctol 2006; 10: 262; discussion 3.

17- Dowidar N, Ebada A, AbouRayah F, AboulSoud M: Pile suture technique for treatment of haemorrhoids versus ligation excision haemorrhoidectomy a randomized trial evaluating clinical effects and anal sphincter manometry. Egyptian Journal of Surgery 2004; 23: 159-166.

18- Festen S, van Hoogstraten MJ, van Geloven AA, Gerhards MF: Treatment of grade III and IV haemorrhoidal disease with $\mathrm{PPH}$ or THD. A randomized trial on postoperative complications and short-term results. Int $J$ Colorectal Dis 2009; 24: 1401-1405.

19- Jeong WJ, Cho SW, Noh KT, Chung SS: One year follow-up result of Doppler-guided hemorrhoidal artery ligation and recto-anal repair in 97 consecutive patients. J Korean Soc Coloproctol; 27: 298-302.

20- Giordano P, Overton J, Madeddu F, Zaman S, Gravante G: Transanal hemorrhoidal dearterialization: A systematic review. Dis Colon Rectum 2009; 52: 1665-1671.

21- Faucheron JL, Gangner Y: Dopplerguided hemorrhoidal artery ligation for the treatment of symptomatic hemorrhoids: Early and three-year follow-up results in 100 consecutive patients. Dis Colon Rectum 2008; 51: 945-949.

22- Walega P, Scheyer M, Kenig J, Herman RM, Arnold S, Nowak M, Cegielny T: Two-center experience in the treatment of hemorrhoidal disease using Doppler-guided hemorrhoidal artery ligation: Functional results after 1-year follow-up. Surg Endosc 2008; 22: 2379-2383. 